\title{
Role of Gender-Based Emotional Intelligence in Corporate Financial Decision-Making
}

\author{
Zou Ran ${ }^{1,2}$ \\ Azeem Gul $\mathbb{D}^{3}$ \\ Ahsan Akbar (iD) ${ }^{4}$ \\ Syed Arslan Haider ${ }^{5}$ \\ Asma Zeeshan ${ }^{6}$ \\ Minhas Akbar (D) ${ }^{7}$ \\ 'Kunming LIH SkyCity Rehabilitation \\ Hospital, Kunming, People's Republic of \\ China; ${ }^{2}$ Faculty of Education, Segi \\ University, Kuala Lumpur, Malaysia; \\ ${ }^{3}$ Department of International Relations, \\ National University of Modern \\ Languages, Islamabad, Pakistan; \\ ${ }^{4}$ International Business School, \\ Guangzhou City University of \\ Technology, Guangzhou, 510080, People's \\ Republic of China; ${ }^{5}$ Department of \\ Management, Sunway University Business \\ School (SUBS), Sunway University, No 5, \\ Jalan Universiti, Bandar Sunway, 47500, \\ Selangor Darul Ehsan, Malaysia; \\ ${ }^{6}$ Department of Management Sciences, \\ Bahria University, Islamabad, Pakistan; \\ ${ }^{7}$ Department of Management Sciences, \\ COMSATS University Islamabad (Sahiwal \\ Campus), Sahiwal, 5700, Pakistan
}

Correspondence: Ahsan Akbar Tel +86 I3802400964

Email akbar@gcu.edu.cn
Purpose: Business competition is getting more intense nowadays, and corporate survival is getting harder; consequently, corporate managers have to make financial decisions in complex and globalized scenarios. As a result, in order to compete in today's global economy, businesses are contemplating incorporating behavioural components of human psychology into their decision-making processes. Corporations are masters of quantitative analysis, but they rarely pay attention to behavioural elements of organizational success. Emotional intelligence is important in many parts of life; therefore, it is crucial to look at its dimensions when it comes to corporate financial decision-making.

Methods: A simple random sampling technique was used to collect data from 200 seniorlevel managers from the corporate sector located in the twin cities of Rawalpindi and Islamabad of Pakistan. SPSS version 22 was used to test the hypotheses.

Results: Results of the study show the gender-based variation in corporate financial decision-making detailing the higher impact of EI of males on CFD than their counterparts in the corporate sector organizations. The elements of self-awareness, empathy, motivation and self-regulation affect the financial decision-making of both the genders with varying degrees of influence, whereas social skills do not affect CFD of both genders.

Conclusion: The study findings explicate that the influence of self-awareness and empathy constructs of EI on corporate financial decisions is stronger in female managers than their male counterparts. However, male managers exhibit a significantly stronger influence of motivation, social skills, and self-regulation dimensions on their financial decisions compared to female managers in a corporate setting. Overall, the impact of EI on CFD is slightly higher in male managers. These empirical outcomes imply that organizations should assess the employees not only for technical skills but also based on their emotional intelligence during the recruitment process.

Keywords: emotional intelligence, self-awareness, self-regulation, social skill, empathy, motivation, corporate financial decision, recruitment process, training and development

\section{Introduction}

Corporate finance has witnessed tremendous advancements in the wake of globalization and gained much research traction in recent decades. The financial crisis hit the global economy in the year 2007. ${ }^{1,2}$ It has been a concern for financial decisionmakers (ie chief executive officer (CEO), senior managers and operational managers) and the researchers because several economies are still facing depression, which can lead to a global financial crisis. ${ }^{3}$ There is a consensus among scholars that emerging issues due to economic recession and depression need robust solutions. ${ }^{4}$ Declining economic trends negatively impact overall organizational culture along with implications for employee (human) psychology, their corporate 
behavior, and, hence, on the financial decision-making patterns. ${ }^{5,6}$ Empowered and emotionally stable employees can help their organizations deal with internal and external setbacks. It is, therefore imperative to analyze the financial crisis and diminishing returns through the prism of emotional intelligence and its impact on financial behavior. In the past, the researchers only examined the resolution of financial issues through quantitative aspects of corporate finance, but now the focus has shifted to the behavioral aspects of financial markets.

Researchers have studied various aspects of finance, but limited studies have examined the importance of emotional intelligence (EI) while making corporate financial decisions (CFD). ${ }^{7}$ When faced with dynamic business conditions, emotional intelligence has an intriguing aspect: game theory has been used in the current research to understand the relationship among how financial decision-makers adapt to ever-changing emotional emotions. ${ }^{8}$ When presented with a difficult circumstance, financial executives have a tendency to act in a variety of ways. When things are going well, managers show optimism and make more riskier actions, which can occasionally lead to bad judgement. ${ }^{9}$ On the other hand, during turbulent times, individuals avoid risk and tend to play a safe. ${ }^{10}$ In this way, emotions (internal factors) and stressful situations (internal feelings and external pressures) may lead to inaccurate managerial assessments about business investment choices. Annual budgeting, ${ }^{11,12}$ capital investments, capital structure options, working capital management, ${ }^{12-14}$ and dividend policy are just a few of the important decisions that must be made by managers in a corporate setting. ${ }^{15}$ The most common definition of financial decision-making is how institutions and consumers understand and implement expert investment advice. However, it should also cover organizational operational problems, such as capital budgeting and assessment. ${ }^{16,17}$ Financially, there is also a negative side to EI that may increase the dangers of poor financial judgments. The landscape of selecting the appropriate blend of raw intelligence and emotional equilibrium may frequently decide how thorough financial recommendations are and how well they are received by the management team responsible for putting such decisions into action.

In the wake of the above discussion, the current study examines the association between gender-based emotional intelligence and corporate financial decision-making. Gender difference in emotional intelligence levels within the financial sector is quite evident and has several important aspects of being researched. Thus, researchers must realize that in the workplace, various genders attempt to exhibit dramatically varied degrees of self-awareness, social competence, emotional conduct, and the capacity to interact with others. As a result, research is needed to determine who is better at regulating and comprehending emotions, as well as who successfully uses emotions while forming connections. ${ }^{18}$ The emotional dimension of human beings has historically been associated with the female gender, which has been shown to experience good and negative emotions more intensely than their male counterparts. ${ }^{19}$ These findings have fueled the notion that women are more emotional, which is still commonly accepted. ${ }^{20}$

It is necessary to examine how women and men act emotionally while making financial decisions. Individual staff variables, which are influenced by the leader's EI, should be factored into effective financial management. Since high EI is linked to optimum team performance and has a favorable impact on task results, the group leader of an organization must build the company's "emotional capital" in order to solve issues like morale, organizational stress, staff turnover, and work-life balance. ${ }^{21}$ Determination of gender-based variation in the emotional intelligence and its ultimate impact on the corporate decision-making has a direct association with the corporate agility. A successful leader needs recognition of the concept of emotional capital and its implication for the recruitment process of new employees and development of the existing employees on the deficient areas that affect influence their job performance and decision-making capabilities.

Investigations into gender differences in CFD measurements yielded mixed results across a variety of geographical areas and sample types. Some research revealed no significant gender differences in $\mathrm{CFD},{ }^{22}$ while others found male, ${ }^{23}$ and some showed female was comparatively better in CFD. ${ }^{18}$ There were also mixed results when it came to gender differences in EI. Although some research found no differences in EI between males and females, ${ }^{24}$ while others found males to be higher in $\mathrm{EI}^{21}$ while other studies found females to be higher in $\mathrm{EI}^{25,26}$ People with a high EI are reported to be better at problem-solving, more confident, and skilled communicators, which are described as disposition or inclinations of CFD. Further, Fernández-Berrocal et $\mathrm{al}^{19}$ reported that female possess greater emotional knowledge. Emotional information has been found to play an important role in decision-making and CFD conditions also help to make informed decisions. Therefore, it can be assumed that EI may have a significant impact on the status of CFD in women, however Ebrahimi and Moafian $^{27}$ reported an unimportant gender role between EI 
and decision-making. However, speculative assumptions about the role of gender in relation to the status of EI and CFD have been challenged by the combined effects of the relationship between EI and CFD potential. Therefore, whether gender will significantly moderate the association between EI and CFD requires further empirical testing.

\section{Literature Review}

\section{Underpinning Theory}

Game theory can be concluded as the analysis of conflict, competitive situation, emotional intelligence and decisionmaking using mathematical models. This theory was introduced in 1950, by the mathematician by the name of John von Neumann and Oskar Morgenstern. John, at the same time, is also an expert in economy. ${ }^{28}$ Game theory can also be defined as the best decision-making in the presence of competitors with different goals. The aim of this theory is to provide the systematic ways for business owner in decision-making. ${ }^{29}$

Game theory helps in settling the problem in many cases and achieving common results. ${ }^{30}$ This theory can be applied in many fields such as marketplace decision, government cases, war, any science context, economics and also finance. In the marketplace, there are competitions between two companies that compete for a competitive edge fighting over the market share. ${ }^{31}$ The implications of game theory might help managers in developing an appropriate market strategy such as pricing or other important decisions. Individuals may also use game theory to predict and recognize the intents of their opponents, as well as to identify the best course of action if their opponent surprises them with unexpected moves. ${ }^{32}$ As a whole, game theory aims to find out the best strategy to solve the problem.

\section{Hypotheses Development}

Finance is a practitioner's discipline, with various models being used for specific reasons by the chief financial officer (CFO) or financial analyst. The rest of the variables are considered to be constants. ${ }^{33}$ Emotions, genetics, heredity, gender, biasness, and culture were first deemed ineffectual in financial decision-making by the researchers. ${ }^{16}$ Researchers have learned throughout time that, despite having adequate models to build future cash flow projections, anticipated needed rates of return, compute discounted cash flows, and develop capital expenditure ("capex") presentations, they are unable to do so.
These models are critical; no one can deny that, but researchers are unable to account for emotions and other such aspects while making financial decisions. As little as $10 \%$ to $25 \%$ of the variance in work performance can be attributed to intelligence quotient (IQ). ${ }^{34}$ Emotional intelligence allows the mind to operate, even if intellect is necessary for good financial judgments. EI has been proven to be a stronger predictor of overall work success, team project performance, and individual leadership in several recent studies. $^{24,35}$

Managing emotions in yourself and others is an EI element that must be identified, used, and understood before it can be effectively managed. Emotional management, on the other hand, may have both beneficial and bad consequences for oneself and others. Following Salovey and Mayer's initial EI measure, ${ }^{36}$ Goleman suggested that having EI alone is insufficient: one must also be skilled in using EI and its many components. ${ }^{37}$ Therefore, Goleman $^{37}$ incorporates dimensions that are entirely distinct from Emotional Competency Inventory's four-factor framework, which is focused on self-awareness, empathy, self-regulation, social competence, and motivation.

\section{Self-Awareness}

Self-awareness is the capacity to identify one's emotions, strengths, flaws, motivations, values, and objectives, as well as their influence on others while making decisions based on gut feelings. It is being "conscious of both our emotions and our ideas about that feeling." Goleman ${ }^{37}$ defined it as being "aware of both our mood and our thoughts about that mood". Caldwell and Hayes ${ }^{38}$ assert that individuals with a high level of self-awareness may better detect and explain their moods and utilize the knowledge to influence their actions. They explained that instilling self-awareness is similar to telling someone, "Before you act, take a minute to consider who you are and what you believe to be true." What is the best course of action in view of these considerations? According to Morin and Everett, ${ }^{39}$ Self-awareness is a sort of schema that includes all the information we have about ourselves.

Furthermore, because this information is digested more thoroughly and is better structured than other types of information, it is recalled more quickly. According to Caldwell and Hayes, ${ }^{38}$ self-awareness improves people's lives in a variety of ways. High self-awareness, according to Jordan and Ashkanasy, ${ }^{40}$ allows people to watch and monitor their own actions. Furthermore, it is necessary for 
good on-the-job performance since it allows people to respond correctly to a variety of interpersonal situations that might occur in the workplace, such as irate clients, dishonest coworkers, and demanding employers. Individuals with poor self-awareness, on the other hand, lack the knowledge needed to make smart judgments about how they react to people and circumstances. ${ }^{41}$

Furthermore, according to the research, self-awareness is a critical component of leadership ability. Self-awareness, according to Daud, ${ }^{42}$ is the first step toward becoming a leader. Many leaders have made professional and organizational errors due to a lack of self-awareness. ${ }^{43}$ According to Carden et al, ${ }^{44}$ self-awareness is often disregarded in corporate environments, despite the fact that it serves as the foundation for the other EI characteristics. Hence, leaders must be able to recognize their own emotions in order to be able to regulate them. Moreover, it is important to recognize one's own feelings in order to comprehend the emotions of others, which is empathy. Self-aware leaders make decisions based on their beliefs, intentions, and desires, and their actions ultimately reflect what feels right to them. Self-aware leaders use time to reflect on themselves and develop critical thinking, which allows them to make decisions based on their life experience. Self-aware leaders learn to trust their gut feelings and see that they provide important information, according to Goleman et $\mathrm{al}^{45}{ }^{45}$ especially when solutions are not available from other sources.

Hypothesis 1: There is a significant difference between gender on self-awareness with financial decision making.

\section{Empathy}

Empathy has been a notion in banking and economics since at least the seventeenth century. ${ }^{46}$ It is defined as the ability to put oneself in another person's shoes and so share their feelings or ideas. Smith's ${ }^{47}$ theory of moral sentiments elaborates empathy as to imagine ourselves in another person's situation and thus understand what it feels like to be in specific circumstances. Empathy, on the other hand, has a far broader function in Smith's work and is mentioned in his Wealth of Nations, simply because it facilitates effective commerce between economic actors, as Fontaine ${ }^{46}$ demonstrates. Indeed, if one wished to make a proposal, one had to do it in a way that appealed to the trade partner's self-love. ${ }^{48}$ To do this, traders must put themselves in the shoes of the other party and observe how they behave in certain conditions. However, there is no indication that later economists picked up on this idea of a new shift in viewpoints. ${ }^{46}$

One could wonder why issues of empathy vanished from the economics literature for so long. One explanation is that as economic theory evolved and codified in the twentieth century, nearly all the focus was placed on the concept of anonymous people fulfilling particular axioms of rationality and interacting solely through the market. The concept that people could desire or need to put themselves in the shoes of others has no place in such a worldview. However, as game theory evolved, such a notion grew increasingly important. ${ }^{30}$ Individuals engage directly and deliberately with one another in this scenario. In fact, game theory assumes that this contact is strategic. Unlike the normal economic model, that framework includes what is known as the "common knowledge" assumption. ${ }^{31}$ It implies that those engaged consider the behaviors of others with whom they contact and are aware that others do the same.

As Binmore ${ }^{32}$ makes out, empathy should not be seen of as a side effect to be noted in passing, but rather as a fundamental human quality that allows us to comprehend the nature of strategic relationships between persons. As a result, Homo economics must be sympathetic in some way. ${ }^{32}$ Empathy must be founded on experiences with other people if it is to condition how individuals anticipate and coordinate each other's behavior. These encounters enable the empathizers to have a deeper understanding of the other person's situation. ${ }^{49}$ The sentimental idea of empathy is one of the main reasons why economists have recently grown more interested in this ability.

While a renewed sense of compassion is a way of gathering information about the interests of others, beliefs, and purposes, the full use of economic empathy has become a tool for building social order based on demographic comparisons. It is important to be clear about who chooses to be involved in this situation. Two different concepts of empathy have been suggested ${ }^{46}$ in these three optional social literature: partial sensitivity identification, which refers to thoughtful transformation of the other, and complete empathy identification, which refers to the assumed change in the status quo. That is, in the first case, a person keeps his own decisions, but in the second case, one accepts another person's preference.

Another source of interest in sensitivity is the recent economic and experimental economic development, which has now begun to incorporate empathy, among many other emotions caused by an economic agent thought to promote 
good behavior, as one of the many emotions caused by an economic agent. Behavioral finance aims to understand the nature of human brain activity when making economic decisions, frequently in the setting of standard economic experiments like the ultimatum game..$^{50,51}$ As a result, we can say that empathy is concerned with three main areas: (i) game theory and the common knowledge assumption, (ii) welfare economics and interpersonal utility comparisons, and (iii) behavioral finance, which examines how people learn about others' preferences, on the one hand, and the idea that other-regarding preferences may or may not lead to non-selfish behaviour on the other.

Hypothesis 2: There is an association between genderbased empathy and corporate financial decision making.

\section{Self-Regulation}

Self-determination includes the ability to control or redirect emotions, as well as the ability to adapt to changing situations. Emotional intelligence is the ability to recognize one's own emotions as well as those of others. Emotion is well known to play a role in human social and economic decision-making (see, for example, ${ }^{52,53}$ ). People subjectively assess objective aspects of options, such as projected return, ${ }^{54}$ and emotions are thought to impact these subjective assessments. ${ }^{55,56}$ People subjectively assess objective aspects of options such as projected return, and emotions are thought to impact these subjective assessments. However, current research on emotion regulation (ER) shows that humans usually have control over their emotional experiences. ${ }^{57}$ This raises the idea that ER methods may moderate choice consequences related to intense emotions. If that is the case, it is also possible that different regulatory techniques will have distinct decision-making consequences. Emotions have consistently been shown to influence decision-making, whether they are assimilated to the "goodness" or "badness" of action alternatives, ${ }^{58}$ attributed to activation in basic appetite or defensive motivational systems, ${ }^{52,59}$ or reduced to somatic markers associated with current or past behavioural outcomes. Dopaminergic regions in the midbrain and their targets, for example (ie, ventral and dorsal striatum, ventromedial and ventrolateral prefrontal cortex, anterior cingulate cortex).

Even when physiological reactions correctly indicate unfavourable options, ${ }^{53}$ this sort of anticipation can be adaptive to emotions like fear or disgust, which have been proven to impede decision-making. ${ }^{54}$ Because the value of prospects (ie, acts with unknown rewards) is computed in "emotion- cognition brain hubs", 55 the inherent function of emotion in decision is all the more essential. Therefore, behavioral finance has pointed out that the interaction between emotion and decision-making is best studied in environments involving risk (where the decision-maker has perfect information about the stochastic relationship between actions and outcomes) and uncertainty (where the decision-maker does not have complete information) on the stochastic environment (see, for example, Heilman et $\mathrm{al}^{60}$ ). When a person expects or feels an emotion, he or she will frequently employ techniques to manage the situation. As a result, ER, a term that encompasses the mechanisms that govern which emotions we have, when we have them, and how we feel and express them, ${ }^{61}$ may be critical to decision-making and other cognitive processes (eg, Newell \& Bröder, ${ }^{62}$ ). Although various ER methods may be employed (eg, Heilman et al, 2016), most recent research has focused on the most often used ER strategies that operate either before or after emotions are engaged (antecedent-focused ER) (responsefocused ER).

Cognitive scientists have found the process model that differentiates ER strategies based on when they act in the generative emotion process ${ }^{61}$ to be extremely valuable, and this has led to groundbreaking findings on the impact of ER on cognition, physiology, and health (for recent reviews, see Mojsa-Kaja et $\mathrm{al}^{63}$ ). Over the last decade, two distinct ER methods have been actively explored. ${ }^{64}$ Cognitive reappraisal is an antecedentfocused ER approach that reformulates the meaning of an event to change the trajectory of emotional reactions. The other technique, expressive suppression, is a response-focused strategy that includes suppressing actions linked to emotional responses (eg, facial expressions, vocal utterances and gestures). ${ }^{61}$ While both reappraisal and suppression reduce emotional expression, their efficiency in reducing emotional experience varies depending on their timing in relation to the emotion generating process.

Hypothesis 3: There is an association between genderbased self-regulation and corporate financial decisions.

\section{Social Skills}

Managing relationships to move individuals in the desired direction is referred to as social competence. ${ }^{65}$ 
Our work environment encourages us to expand our horizons beyond our department. Interactions are frequently necessary both within and outside the company in areas such as industrial relations, human resources, and marketing, as well as in commercial and investment banking. These interactions are based on our ability to manage relationships, settle conflicts, and work with others. Projects are completed via team cooperation and collaboration. Specific interpersonal skills (ie, the capacity to build and maintain social networks; the ability to deal with subordinates; the ability to sympathize with top-level leaders) were mentioned as important for managing performance by Mintzberg ${ }^{66}$ in his classic book on management abilities. Researchers looked at the significance of broad interpersonal qualities including empathy, social skills, and tact in predicting leadership emergence and success even before 1973 (see Bass, 1990 for a review). Strong interpersonal skills are readily understood by managers, executives, and human resources experts. To guide research, assessment, training, and development of organizational leaders, a shared theoretical framework connecting emotional and social abilities with leadership effectiveness ${ }^{67}$ is required.

Early social skills research largely focused on clinical populations, with social skills evaluation and training being used to better identify and treat particular types of psychopathology or difficulties in psycho-social adjustment. ${ }^{68}$ Emotional and social abilities were linked to more helpful social support networks and higher quality social connections. ${ }^{69}$ Furthermore, a lack of emotional skills has been linked to the development of low social and emotional competence, which can lead to the breakdown of family and other relationships. ${ }^{63}$ Social intelligence includes the ability to express oneself in social interactions, the ability to "read" and grasp a variety of social situations, awareness of social roles, norms, and scripts, interpersonal problem-solving abilities, and social role-playing skills. Surprisingly, despite the fact that social intelligence has been linked to effective social functioning in general $^{70}$ and effective leadership in particular, ${ }^{9}$ no agreed-upon framework describing the specific characteristics of social intelligence or techniques to assess it has been developed. Our emotional and social skills framework, we believe, is not only more condensed than previous models of social and emotional intelligence but it also offers the benefits of accurate evaluation and an emphasis on talents that can be enhanced.
Hypothesis 4: There is an association between genderbased social skills and corporate financial decision making.

\section{Motivation}

Being determined to succeed just for the sake of succeeding. The most noticeable aspect of this activity when determining the content and purpose of work in management is decision-making. ${ }^{5}$ For decision-makers, it is one of the most difficult and crucial managerial responsibilities. ${ }^{15}$ Their knowledge, experience, skills, subjective attitudes, and values all play a role in the decision-making process. ${ }^{71}$ The quality of decision-making activities is primarily reflected in the quality of management. The basic role of Miu et al, ${ }^{72}$ decision is to choose the best choice among the variations in decision-making scenarios (problems). AlDabbagh $^{73}$ defines decision-making as a collection of actions that include diagnosing the problem, creating alternatives, and selecting one of the set of options. The quality of decisions made by managers, according to van Dijk et $a l,{ }^{51}$ is a measure of their effectiveness. The study of decision-making reduces the issues of orientation and decision-making. Allowing an average bright individual to think methodically about complicated, significant, and genuine situations is required for a prescriptive approach to decision-making. This implies that it gives some assistance for systematic thinking in the solution of complicated decision-making issues.

Decision-making and motivation are intertwined and influence each other. The process of decision-making has an impact on the decision-outside maker's and inner motivation. ${ }^{7}$ The ultimate phrasing of the choice is also influenced by motivation. This is likewise true in the other direction. Each stage of decision-making can have a direct or indirect impact on employee motivation and instruments that can favorably affect motivational levels, such as a well-designed motivating programme. One of the internal materials is a motivating programme, which may be viewed as part of an organizational secret. Its work should be based on the most up-to-date understanding about the company's organizational and human resource condition, as well as the company's goal. A manager may influence his employees' motivation through assessment, various types of pay, career planning, and so on. No skill is more valuable in life than the capacity to constructively encourage others. This implies that specific needs must be requested of the director. The only person who can successfully inspire is someone who is self-motivated and 
possesses specific talents and characteristics-creating positive incentives is insufficient. According to Moon, ${ }^{9}$ a positive reward should be linked to tasks to be completed, and the entire process should be set up in such a way that it is manageable within the available monetary resources and time constraints. Yelderman et $\mathrm{al}^{20}$ describe motivation as having access to tasks, the activity, the conditions in which work is being done, and the consequences of the activity.

Hypothesis 5: There is a connection between genderbased motivation and corporate financial decisions.

\section{Corporate Financial Decisions}

Emotions have a surprising amount of predictability when it comes to financial decisions. ${ }^{4,6,16}$ We have a tendency to be overconfident in our knowledge and judgments, to extrapolate recent patterns while disregarding the past, and to fail to accept defeats graciously by clinging to our losers for far too long, among other things. Even the most seasoned investors are vulnerable. ${ }^{74}$ Clearly, decisions made deep within our thoughts have a significant impact on investor and market behaviour. ${ }^{75}$ According to neuroeconomics research, the parts of the brain that control our emotions have a significant impact on how we think about risks and rewards. We regularly make decisions that we consider to be reasonable. Those judgments are still largely dependent on our own feelings, rather than ideas, evidence, or analysis, which is a typical occurrence even among specialists. Participants who were gently touched on the shoulder by a woman were prepared to accept larger financial risks than those who were not touched, ${ }^{76}$ according to a research by Ackert et al, 2020. In another study, Alzoubi and Aziz ${ }^{7}$ discovered that after seeing an image linked to negative emotions, individuals unintentionally made fewer hazardous investing decisions than those viewing neutral pictures. ${ }^{7}$ These and other cognitive failures enable automated traders to profit from others' predicted emotional responses.

\section{Conceptual Framework and Methodology}

Emotional intelligence and company financial choices are the two most important elements. As illustrated in Figure 1, emotional intelligence is split into self-awareness, empathy, self-regulation, social competence, and motivation.

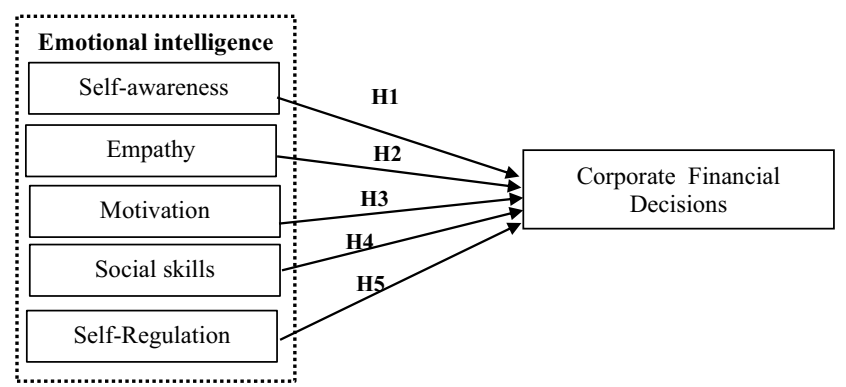

Figure I Research Model.

\section{Research Methodology}

Given the nature of their work and organizational position, several respondents were requested not to reveal their identities in order to assure the survey's validity and objectivity. As a result, personal information, such as name, age, organization, and so on, was left out of the questionnaire as a general rule of thumb. This research is quantitative and is based on primary data collected through structured questionnaires. ${ }^{77}$ The sampling technique used in this study is simple random sampling. ${ }^{78}$ This sampling method is the least biased and helps obtain many complete questionnaires conveniently, and quickly. ${ }^{79}$ The data was collected in 4 months, from February 2021 to May 2021. This study is not a time-lagged study and the data of all constructs were collected at one time, so the design is cross-sectional in nature. ${ }^{80}$ The respondents in this study were project managers and operational managers who worked for different private and public organizations located in twin cities, Rawalpindi and Islamabad, Pakistan. The total population was estimated to be 400 project managers and operational managers. Some of the companies included are: Oil \& Gas Development Company Limited (OGDCL), Defence Housing Authority, Fauji Fertilizer Company. The sample size was calculated using Slovin formula, and the sample size was found to be 200 .

$$
\begin{gathered}
n=\frac{N}{1+N(e) 2} \\
n=\frac{400}{(\{1+400 *(0.05) 2\})} \\
n=200
\end{gathered}
$$

Due to the Covid-19 epidemic, data were collected through self-administered surveys (generated via Google Docs) and distributed across several online channels (Gmail, 
Linked In, Twitter, and Facebook). This allowed the most significant possible number of people to take part in the poll. A total of 250 questionnaires were circulated, out of which only 200 were usable, yielding a response rate of $80 \%$.

\section{Measures}

A 5-point Likert scale was used to account for the factors, with 1 indicating Strongly Disagree, 2 indicating Disagree, 3 suggesting Neutral, 4 indicating Agree, and 5 indicating Strongly Agree. The questionnaire's 80 questions, which measure dependent and independent factors, were adapted from previously published and validated measures. Selfawareness (10-items), self-regulation (10-items), empathy (10-items), social skill (10-items), motivation (10-items), and social skill (10-items) are the five subcategories of emotional intelligence, according to Goleman. ${ }^{37}$ The dependent variable, corporate financial choices, was divided into three components for analysis: Merger \& acquisition (10-items), Dividend policy (10-items), Investment policy (10-items) scales developed by Gietl et al. ${ }^{81}$

\section{Results and Discussion}

This study looked at the impact of emotional intelligence depending on gender on corporate financial choices. Statistical tests such as reliability analysis, regression, and correlation are employed to investigate the relationship. Emotional intelligence and corporate financial decisions were first studied individually, and later they were combined under the key headings. The major heads were then examined together. Because this study combines human psychology and finance (also known as behavioral finance), a variety of technologies were used to evaluate the data and verify the importance of the proposed study, including excel data analysis and SPSS version $22 .{ }^{82}$

\section{Reliability Analysis (Cronbach's Alpha)}

When variables derived from summated scales are employed as predictor components in objective models, reliability takes centre stage. Cronbach's alpha is a numerical reliability coefficient. ${ }^{76}$ The reliability of a test is determined by comparing it to other tests with the same number of items and measuring the same construct of interest..$^{83}$ As a result, we utilized the analysis given in Table 1 to confirm the data's reliability.

Cronbach's Alpha values for all variables utilized in this investigation are shown in Table 1. When Cronbach's Alpha is more than 0.7, according to Falk \& Savalei, ${ }^{84}$ the trustworthiness of the underlying data is adequate. Cronbach's Alpha values for all independent and dependent variables are more than 0.7 in Table 1, indicating that the data in this study is reliable. ${ }^{85}$ For Self-awareness, Self-regulation, Social-skill, Empathy, Motivation, Merger and acquisition, Dividend policy, and Investment policy, the values are 0.91 , $0.897,0.731,0.966,0.945,0.956,0.966$, and 0.720 .

Table 2 shows that there is a link between corporate financial choices and several male emotional intelligence characteristics (motivation, empathy, social skill and selfregulation). As shown by the number (-.0.537) in Table 2, there is a negative association between self-awareness and company financial decisions. Furthermore, the significance of the association coefficient between male motivation and company financial choice is 0.894 . This indicates that the two variables have a fairly favourable relationship. Males' empathy and financial decisions in the workplace have

Table I Reliability Analysis of Variables

\begin{tabular}{|l|c|c|c|c|c|c|c|}
\hline S. No. & Variable & Items & N & $\begin{array}{c}\text { Cronbach's } \\
\text { Alpha }\end{array}$ & Mean & SD & SEM \\
\hline 1 & Self-awareness & 10 & 200 & 0.91145396 & 615.55 & 63.5833901 & 18.9203106 \\
\hline 2 & Self-regulation & 10 & 200 & 0.89775352 & 671.7 & 55.0200872 & 17.5932248 \\
\hline 3 & Social-skill & 10 & 200 & 0.73102085 & 570.1 & 37.318762 & 19.3547042 \\
\hline 4 & Empathy & 10 & 200 & 0.96691048 & 729.5 & 99.1698039 & 18.0395086 \\
\hline 5 & Motivation & 10 & 200 & 0.94562728 & 707 & 72.1761734 & 16.8300103 \\
\hline 6 & Merger \& acquisition & 10 & 200 & 0.95667056 & 630 & 85.264295 & 17.7483809 \\
\hline 7 & Dividend policy & 10 & 200 & 0.96635145 & 743 & 94.0978214 & 17.2608716 \\
\hline 8 & Investment policy & 10 & 200 & 0.72073165 & 570.6 & 36.6502387 & 19.368129 \\
\hline
\end{tabular}


Table 2 Correlation Analysis

\begin{tabular}{|c|c|c|c|c|c|c|c|c|c|c|c|}
\hline Construct & $\begin{array}{l}\text { I CFD } \\
\text { (Male) }\end{array}$ & $\begin{array}{l}2 \text { CFD- } \\
\text { Female }\end{array}$ & $\begin{array}{l}3 \text { MO- } \\
\text { Male }\end{array}$ & $\begin{array}{l}4 \text { MO- } \\
\text { Female }\end{array}$ & $\begin{array}{l}5 \text { EM- } \\
\text { Male }\end{array}$ & $\begin{array}{c}6 \text { EM- } \\
\text { Female }\end{array}$ & $\begin{array}{l}7 \text { SS- } \\
\text { Male }\end{array}$ & $\begin{array}{c}8 \text { SS- } \\
\text { Female }\end{array}$ & $\begin{array}{c}9 \text { SR- } \\
\text { Female }\end{array}$ & $\begin{array}{c}\text { I0 SA- } \\
\text { Male }\end{array}$ & $\begin{array}{l}\text { I I SA- } \\
\text { Female }\end{array}$ \\
\hline CFD-Male & I & & & & & & & & & & \\
\hline CFD-Female & 0.9521 & I & & & & & & & & & \\
\hline MO-Male & 0.8948 & 0.7950 & 1 & & & & & & & & \\
\hline MO- Female & -0.3819 & -0.1839 & -0.7279 & I & & & & & & & \\
\hline EM-Male & 0.9750 & 0.9904 & 0.8712 & -0.3125 & 1 & & & & & & \\
\hline EM- Female & 0.9727 & 0.9935 & 0.8587 & -0.2920 & 0.9996 & 1 & & & & & \\
\hline SS-Male & 0.2730 & 0.1656 & 0.1641 & 0.1223 & 0.1807 & 0.1698 & 1 & & & & \\
\hline SS- Female & 0.1938 & -0.0048 & 0.3169 & -0.3272 & 0.0764 & 0.0542 & 0.8612 & 1 & & & \\
\hline SR-Male & 0.9147 & 0.8113 & 0.9896 & -0.6649 & 0.8833 & 0.8704 & 0.3006 & 0.4137 & 1 & & \\
\hline SR- Female & -0.4960 & -0.4453 & -0.7796 & 0.8524 & -0.5333 & -0.5213 & 0.4058 & 0.0647 & -0.6887 & 1 & \\
\hline SA-Male & -0.5376 & -0.7468 & -0.3700 & -0.1220 & -0.6842 & -0.6994 & 0.4028 & 0.6222 & -0.3269 & 0.3814 & I \\
\hline SA-Female & 0.9222 & 0.9030 & 0.9104 & -0.4132 & 0.9406 & 0.9318 & 0.3844 & 0.3619 & 0.9448 & -0.5429 & -0.4816 \\
\hline
\end{tabular}

Abbreviations: CFD, corporate financial decision; MO, motivation; EM, empathy; SS, social-skill; SR, self-regulation; SA, self-awareness.

a statistically significant connection to 0.974 . Males, on the other hand, have a pretty significant positive relationship between empathy and corporate financial decisions. Male social skills have an insignificant association value of 0.273 with corporate financial decision-making. This shows that the two variables have a considerably less favourable relationship. However, the significant correlation coefficient between self-regulation and corporate financial decisions is 0.914 , indicating a strong positive link between the two variables.

There is a positive link between corporate financial decisions and some emotional intelligence traits (empathy and self-awareness) in the case of females, and a negative association between motivation, self-regulation, social skill, and corporate financial decisions in the case of males. Female motivation and company financial decision have a Pearson correlation of -0.183 , which is a negative connection. The Pearson correlation value of 0.993 for female empathy and corporate financial decision-making is likewise strong. Females have a higher favourable link between empathy and financial decisions made by corporations. ${ }^{25,26,40}$ Female social skills are adversely associated with a company's financial decisions, with a correlation value of -0.0048 . The correlation value between corporate financial decision-making and selfregulation is -0.445 , which indicates that the two variables are likewise negatively linked. The correlation value between selfawareness and company financial choice is 0.903 , indicating a favourable link between the two variables.

\section{Male's Emotional Intelligence in Corporate Financial Decisions}

In this study, regression analysis was used ${ }^{86}$ to see how all the emotional intelligence components impact corporate financial decisions. Table 3 displays the results of regression analysis. The Coefficient of Determination's value $\mathrm{R}^{2}$ discusses the impact of emotional intelligence on corporate financial choices (Self-awareness, self-regulation, social skill, empathy, and motivation). The $\mathrm{R}^{2}$ value of social skills is 0.0740 . This indicates that social competence accounts for $7 \%$ of the variance in a corporate financial decision, whereas other factors account for $93 \%$ of the variance.

This indicates that social competence has a little impact on corporate financial decisions in male respondents. In male, the coefficient of determination for self-regulation is 0.836. This indicates that self-regulation influences $83 \%$ of financial decisions made by corporations. Other factors account for the remaining 17\%. Empathy has a coefficient of determination of 0.95 . This indicates that empathy in male accounts for $95 \%$ of the diversity in corporate financial choices, with the remaining $5 \%$ owing to unknown causes. The result for motivation is $0.8 \%$, suggesting that motivation accounts for $80 \%$ of the variation in corporate financial decisions, while other factors account for $20 \%$. The value of $\mathrm{R}^{2}$ in the instance of male self-awareness is 0.028 , which indicates that self-awareness influences corporate financial choices by just $2.8 \%$. 
Table 3 Male Respondent's Regression Analysis

\begin{tabular}{|l|r|r|r|r|}
\hline Variable & \multicolumn{1}{|c|}{ R } & R Square & \multicolumn{1}{|l|}{$\begin{array}{l}\text { Adjusted } \\
\text { R Square }\end{array}$} & $\begin{array}{l}\text { Std. Error } \\
\text { of the } \\
\text { Estimates }\end{array}$ \\
\hline Social skill & 0.273 & 0.074 & -0.233 & 310.98 \\
\hline Self-regulation & 0.914 & 0.836 & 0.782 & 130.644 \\
\hline Empathy & 0.974 & 0.950 & 0.943 & 71.86 \\
\hline Motivation & 0.894 & 0.800 & 0.734 & 144.33 \\
\hline Self-awareness & 0.537 & 0.289 & 0.052 & 272.58 \\
\hline
\end{tabular}

Table 4 reveals that in the case of male, the total emotional intelligence coefficient of determination value is 0.90 , implying that emotional intelligence accounts for $90 \%$ of the variation in corporate financial choices. Other factors account for $10 \%$ of the variance. The total emotional intelligence coefficient of determination value for girls is 0.809. Emotional intelligence has an $80 \%$ effect on corporate financial choices among women. Overall, both males and females have emotional intelligence while making financial decisions, however males have a somewhat higher overall coefficient of determination than females, ${ }^{25,26}$ as seen in Table 4.

Table 5 shows that several of the independent and dependent factors have a positive and substantial relationship. The t-values for the male self-regulation, empathy, and motivation factors are all more than 2 , indicating that the variables have a substantial impact. The F-values for male self-management, empathy, and motivation are all more than 4, suggesting statistical significance in all three areas. However, at the 5\% significance level, selfawareness and social skills values are negligible, suggesting a poor relationship of these qualities with corporate financial decisions in the case of male. ${ }^{21}$

\section{Female's Emotional Intelligence in Corporate Financial Decisions}

Female social abilities have an $\mathrm{R}^{2}$ score of 0.022 . As demonstrated in Table 6 , social skill accounts for just $2 \%$ of the variance in corporate financial decisions, while the other $98 \%$

Table 4 Cumulative Gender-Based El Regression Analysis

\begin{tabular}{|l|c|c|c|r|}
\hline Variable & R & R Square & $\begin{array}{c}\text { Adjusted } \\
\text { R Square }\end{array}$ & $\begin{array}{r}\text { Std. Error of } \\
\text { the Estimate }\end{array}$ \\
\hline El Male & 0.953 & 0.909 & 0.878 & 97.49 \\
\hline El Female & 0.899 & 0.809 & 0.745 & 28.180 \\
\hline
\end{tabular}

Table 5 Coefficients (Males)

\begin{tabular}{|l|c|c|c|c|}
\hline Variable & $\begin{array}{c}\text { Standardized } \\
\text { Coefficient Beta }\end{array}$ & t Value & p-value & F \\
\hline Social skill & 6.36 & 0.49 & 0.65 & 0.2416 \\
\hline Self-regulation & 1.90 & 3.92 & 0.029 & 15.36 \\
\hline Empathy & 1.526 & 7.59 & 0.0047 & 57.69 \\
\hline Motivation & 1.195 & 3.47 & 0.040 & 12.04 \\
\hline Self-awareness & -8.81 & -1.10 & 0.35 & 1.21 \\
\hline
\end{tabular}

Table 6 Female Respondent's Regression Analysis

\begin{tabular}{|l|r|r|r|r|}
\hline Variable & \multicolumn{1}{|c|}{$\mathbf{R}$} & R Square & $\begin{array}{r}\text { Adjusted } \\
\text { R Square }\end{array}$ & $\begin{array}{r}\text { Std. Error of } \\
\text { the Estimate }\end{array}$ \\
\hline Social skill & 0.0047 & 0.022 & -0.333 & 64.49 \\
\hline Self-regulation & 0.445 & 0.198 & -0.0689 & 57.75 \\
\hline Empathy & 0.993 & 0.987 & 0.982 & 71.86 \\
\hline Motivation & 0.183 & 0.033 & -0.288 & 7.327 \\
\hline Self-awareness & 0.903 & 0.815 & 0.753 & 27.710 \\
\hline
\end{tabular}

is attributed to other variables. In the case of female respondents, this indicates that social competence has a limited impact on corporate financial decisions. Self-regulation in females has a coefficient of determination of 0.198 . This indicates that self-regulation influences $19 \%$ of the financial decisions made by corporations. Other factors account for the remaining $81 \%$ of the total. Self-regulation has a far less impact on women's financial decisions in the workplace. Empathy has a coefficient of determination of 0.987 . This indicates that female empathy accounts for $98 \%$ of the difference in corporate financial choices, with the remaining $2 \%$ owing to unknown causes. Motivation has a score of 0.033 , showing a $3 \%$ variance in corporate financial decisions due to motivation and a 97\% effect from other factors, demonstrating a very weak link. The value of $\mathrm{R}^{2}$ in the instance of female selfawareness is 0.815 , which implies that self-awareness influences corporate financial choices by $81 \%$.

Table 7 shows that certain independent and dependent factors have a positive and substantial relationship. The t-values for the female self-awareness and empathy factors are greater than 2, indicating that the variables have a substantial impact. Females' self-awareness and empathy have F-values greater than 4, indicating statistical significance in these areas. Self-regulation, motivation, and social skill values, on the other hand, do not meet the established 
Table 7 Coefficient Analysis (Females)

\begin{tabular}{|l|l|l|l|l|}
\hline Variable & $\begin{array}{l}\text { Standardized } \\
\text { Coefficient Beta }\end{array}$ & t Value & $\mathbf{p}$ value & $\mathbf{F}$ \\
\hline Social skill & -0.0178 & -0.0083 & 0.99 & 6.88 \\
\hline Self-regulation & -1.63 & -0.86 & 0.45 & 0.74 \\
\hline Empathy & 0.644 & 15.148 & 0.00062 & 229.46 \\
\hline Motivation & -0.287 & -0.324 & 0.76 & 0.015 \\
\hline Self-awareness & 5.96 & 3.64 & 0.035 & 13.25 \\
\hline
\end{tabular}

requirements, indicating that females have inadequate links with corporate financial decisions. ${ }^{90}$ This is significant if the $\mathrm{P}$-value is less than 0.05. So, the P-value for self-management, drive, and social competence among females is more than 0.05 , indicating that they have a very poor association with corporate financial choices. In light of the data gathered and correlation and regression analysis, all the presented hypotheses were accepted. This emphasizes the significance of the research. Some aspects of male emotional intelligence and some aspects of female emotional intelligence have a negative association with corporate financial choices in the case of gender-based emotional intelligence. ${ }^{5,7}$ Some male and female emotional intelligence characteristics, on the other hand, were shown to be favorably related with corporate financial decision-making. ${ }^{19,27}$

\section{Conclusions and Implications}

The primary purpose of conducting this research was to uncover the association between gender-based emotional intelligence and corporate financial decision-making. To compete in the globalized environment, corporations have to consider gender equality and diversity in all organizational aspects. $^{22,26}$ There has been burning debates on developing skillset, education and capacity among the employees of both genders. ${ }^{35}$ The requirements in this regard have been researched and evaluated both from literary and practical organizations' perspectives. However, the focus remains quantitative, where corporations have a firm grip on evaluating the outcomes in tangible profit terms. ${ }^{88}$ However, behavioral aspects, including emotional intelligence and its genderbased diverse implications, remained neglected. ${ }^{25,26}$ Emotional intelligence is an essential consideration in every aspect of life in general and for enhancing employees' performance in organizations in particular. ${ }^{87}$ Because emotional intelligence involves the capacity to understand what managers are experiencing and how they control their emotions during key choices, the confluence of emotional intelligence and financial decision-making is critical. ${ }^{57} \mathrm{EI}$ enhances the underlying reasoning of the decision-makers and optimizes their ability to make appropriate financial decisions.

The findings of the present study depict that there is a gender-based variation in the corporate financial decisions due to varying degrees of emotional intelligence (Self-awareness, Self-regulation, social skill, Empathy, and Motivation) in male and female managers. Moreover, the influence of selfawareness and empathy constructs of EI on corporate financial decisions is stronger in female managers than their male counterparts. One of the causes of the recent economic crisis, according to Vasconcelos, ${ }^{88}$ is multinational businesses losing contact with the stakeholders they serve. The authors believe that incorporating empathy into their decision-making without compromising commercial judgement might be part of the answer to the problem. As a result, it would be prudent to argue that a female manager is capable of identifying and regulating both conscious and subconscious emotional drivers in herself and others (and skillfully managing such sensitive situations for her stakeholders). Given the chance to appropriately channel those inclinations into concrete things, they would be capable of producing enormous power and wealth. Therefore, emotions may be both beneficial and destructive in the economic world. ${ }^{6}$ Thus, the importance of empathy in organizational performance should not be overlooked.

However, male managers exhibit a significantly stronger influence of motivation, social skills, and self-regulation dimensions on their financial decisions than female managers in a corporate setting. Overall, the impact of EI on CFD is slightly higher in male managers. These empirical outcomes imply that organizations should assess the employees not only for technical skills but also based on their emotional intelligence during the recruitment process. Besides, gender-based variations in EI should be of special focus during on-the-job training and development of managers to optimize the corporate financial decision-making process. For existing employees, management should continually conduct capacity development programs to sharpen the team's financial acumen and attain a balance in their personal, professional competence (self-awareness and self-confidence) and social competence. ${ }^{89}$

Successful CEOs should be aware of mental models, evaluate previous mistakes, incorporate different thinking, handle disputes, and reduce the perpetuating effects of erroneous pattern recognition to guarantee organizational adaptability. ${ }^{90}$ It is feasible to do this by fostering business emotional intelligence with the same zeal that has historically been devoted toward financial profits. Because the confluence of emotional 
intelligence and financial decision-making is critical for properly optimizing financial decision-making, a financial team with the best combination of skills and talents, including analytical and emotional intelligence, should be recruited and taught. $^{35,70}$ The current research results will help managers identify and focus on the attributes of emotional intelligence factors that contribute more towards corporate financial decision in male and female managers. Keeping in view, the top management can assign responsibilities to the male and female managers based on their EI strengths to boost organizational performance. $^{91}$

\section{Limitations of the Study and Future Projections}

There are a few limitations to this study that might be used as research possibilities in the future. Due to time and budget restrictions, the sample size for this study is small. Moreover, this research is not industry-specific, which is a weakness and a strength because it adds to the applicability generalization of the results to myriad industries. Future studies in this domain can investigate the impact of emotional intelligence on corporate decision-making with special reference to a particular industry or comparison between different industrial segments by employing a relatively larger sample. Lastly, in the present study, the data were collected through online surveys due to COVID-19 pandemic, and we only focused on the influence of EI based on five-dimensional social skills, self-regulation, empathy, motivation and self-awareness on CFD. Self-awareness in male and social skills, self-regulation and motivation in female put negative impact on CFD. It will be interesting for future studies to collect data through interviews and compare their findings with the current study results. We also extend the model by examining how EI impacts employee satisfaction and well-being and boosts their performance in other areas of corporate decision-making. Future line of research can also explore the role of EI in the success of women entrepreneurs. ${ }^{92}$

\section{Ethical Approval}

The Institutional Review Board (IRB) of the Quaid-e-Azam University, Islamabad, approved this study (2021-826). The study subjects gave their consent, and the principles specified in the Declaration of Helsinki were followed.

\section{Acknowledgments}

We would like to thank the three anonymous reviewers for their valuable comments on an earlier version of this article.

\section{Funding}

The study has not received any external funding from any sponsor or donor agency.

\section{Disclosure}

The authors reported no conflict of interest.

\section{References}

1. Sirui W. Comparison between the COVID-19 epidemic and global credit crisis in 2008. Paper presented at: 6th International Conference on Financial Innovation and Economic Development (ICFIED 2021); 2021.

2. Zulaykho K, Shakhnoza A. World experience of social protection of the population in the context of economic crises. J CIBG. 2021;27 (4): 1.

3. Akbar M, Akbar A, Draz MU. Global financial crisis, working capital management, and firm performance: evidence from an Islamic market index. SAGE Open. 2021;11(2):21582440211015705. doi:10.1177/ 21582440211015705

4. Bouslah K, Kryzanowski L, M'Zali B. Social performance and firm risk: impact of the financial crisis. $J$ Bus Ethics. 2018;149 (3):643-669. doi:10.1007/s10551-016-3017-x

5. Iram T, Bilal AR, Latif S. Is awareness that powerful? Women's financial literacy support to prospects behaviour in prudent decision-making. Glob Bus Rev. 2021;0972150921996185. doi:10.1177/ 0972150921996185

6. Ta PHAN, Lh DUONG. The effects of corporate governance mechanisms on firm performance: empirical evidence from Vietnam. J Asian Finance Econ Bus. 2021;8(4):369-379.

7. Alzoubi HM, Aziz R. Does emotional intelligence contribute to quality of strategic decisions? The mediating role of open innovation. J Open Innov Technol Mark Complex. 2021;7(2):130. doi:10.3390/joitmc7020130

8. Cui Y. The role of emotional intelligence in workplace transparency and open communication. Aggress Violent Behav. 2021;101602. doi:10.1016/j.avb.2021.101602

9. Moon J. Effect of emotional intelligence and leadership styles on risk intelligent decision making and risk management. J Eng Proj Prod Manag. 2021;11(1):71-81. doi:10.2478/jeppm-2021-0008

10. Akbar M, Akbar A, Maresova P, Yang M, Arshad HM. Unraveling the bankruptcy risk-return paradox across the corporate life cycle. Sustainability. 2020;12(9):3547. doi:10.3390/su12093547

11. Akbar A, Jiang X, Akbar M. Do working capital management practices influence investment and financing patterns of firms? $J$ Econ Admin Sci. 2020. doi:10.1108/JEAS-07-2019-0074

12. Wang Z, Akbar M, Akbar A. The interplay between working capital management and a firm's financial performance across the corporate life cycle. Sustainability. 2020;12(4):1661. doi:10.3390/su12041661

13. Khan N, Akbar M, Akbar A. Does an optimal working capital exist? The role of financial constraints. Res J Finance Account. 2016;7 (9):131-136.

14. Akbar A. Working capital management and corporate performance: evidences from textile sector of China. Eur Acad Res. 2014;2 (9):11440-11456.

15. Quaicoe A, Eleke-Aboagye PQ. Behavioral factors affecting investment decision-making in bank stocks on the Ghana stock exchange. In: Qualitative Research in Financial Markets; 2021.

16. Goyal K, Kumar S, Xiao JJ. Antecedents and consequences of personal financial management behavior: a systematic literature review and future research agenda. Int J Bank Mark. 2021;39 (7):1166-1207. doi:10.1108/IJBM-12-2020-0612 
17. Khan I, Afeef M, Jan S, Ihsan A. The impact of heuristic biases on investors' investment decision in Pakistan stock market: moderating role of long term orientation. In: Qualitative Research in Financial Markets; 2021.

18. Jiang X, Akbar A. Does increased representation of female executives improve corporate environmental investment? Evidence from China. Sustainability. 2018;10(12):4750. doi:10.3390/su10124750

19. Fernández-Berrocal P, Cabello R, Castillo R, Extremera N. Gender differences in emotional intelligence: the mediating effect of age. Behav Psychol. 2012;20(1):77-89.

20. Yelderman LA, Estrada-Reynolds V, Lawrence TI. Release or denial: evaluating the roles of emotion and risk in parole decisions. Psychol Rep. 2021;00332941211007929. doi:10.1177/ 00332941211007929

21. Newman M, Smith KH. Emotional intelligence and emotional labour: a comparison study using the emotional capital report (ECR). Educ Soc. 2014;32(1):41-62. doi:10.7459/es/32.1.04

22. Gao W, Ping S, Liu X. Gender differences in depression, anxiety, and stress among college students: a longitudinal study from China. J Affect Disord. 2020;263:292-300. doi:10.1016/j.jad.2019.11.121

23. Hurley D, Choudhary A. Role of gender and corporate risk taking. Corp Gov. 2020;20(3):383-399. doi:10.1108/CG-10-2018-0313

24. Yang R, Díaz VG, Hsu C-H. Use of emotional intelligence to promote innovation among employees in the work environment through qualitative and quantitative analysis. Aggress Violent Behav. 2021;101589. doi:10.1016/j.avb.2021.101589

25. Hyde J, Grieve R, Norris K, Kemp N. The dark side of emotional intelligence: the role of gender and the Dark Triad in emotional manipulation at work. Aust $J$ Psychol. 2020;72(4):307-317. doi:10.1111/ajpy.12294

26. Martínez-Marín MD, Martínez C, Paterna C. Gendered self-concept and gender as predictors of emotional intelligence: a comparison through of age. Curr Psychol. 2021;40(9):4205-4218. doi:10.1007/ s12144-020-00904-z

27. Ebrahimi MR, Moafian F. Does emotional intelligence or self-efficacy have something to do with high school English teachers' critical thinking, considering demographic information? Int J Linguist. 2012;4(4):224

28. Shari NSM, Shamsudin MF. Can game theory solve marketing problems? JPCBR. 2020;5(1):20.

29. Keith T. Conceptual analysis of behavioral theories/models: application to financial behavior. Eur J Soc Sci. 2011;18(3):386-404.

30. Aumann RJ. What is game theory trying to accomplish? Paper presented at: Frontiers of Economics. edited by Arrow K, Honkapohja S; 1985.

31. Van Damme E. On the state of the art in game theory: an interview with Robert Aumann. Games Econ Behav. 1998;24(1-2):181-210. doi:10.1006/game.1997.0612

32. Binmore KG. Game Theory and the Social Contract: Just Playing. Vol. 2. MIT press; 1994.

33. Nyberg AJ, Cragun OR, Schepker DJ. Chief executive officer succession and board decision making: review and suggestions for advancing industrial and organizational psychology, human resources management, and organizational behavior research. Annu Rev Organ Psychol Organ Behav. 2021;8(1):173-198. doi:10.1146/ annurev-orgpsych-012420-061800

34. Shankar S, Tewari V. Impact of collective intelligence and collective emotional intelligence on the psychological safety of the organizations. Vision. 2021;09722629211012256. doi:10.1177/ 09722629211012256

35. Román-Calderón JP, Aguilar-Barrientos S, Escalante JE, Barbosa J, Arias Salazar A. The effect of student work group emotional intelligence on individual task performance in teams. $J$ Exper Educ. 2021;44(2):121-136. doi:10.1177/1053825920940342

36. Salovey PE, Sluyter DJ. Emotional Development and Emotional Intelligence: Educational Implications. Basic Books; 1997.
37. Goleman D. An EI-Based Theory of Performance. The Emotionally Intelligent Workplace: How to Select For, Measure, and Improve Emotional Intelligence in Individuals, Groups, and Organizations. Vol. 1;2001: 27-44. Consortium for Research on Emotional Intelligence in Organizations (www.eiconsortium.org).

38. Caldwell C, Hayes LA. Self-efficacy and self-awareness: moral insights to increased leader effectiveness. J Manag Dev. 2016;35 (9):1163-1173. doi:10.1108/JMD-01-2016-0011

39. Morin A, Everett J. Inner speech as a mediator of self-awareness, self-consciousness, and self-knowledge: an hypothesis. New Ideas Psychol. 1990;8(3):337-356. doi:10.1016/0732-118X(94)90020-5

40. Jordan PJ, Ashkanasy NM. Emotional intelligence, emotional selfawareness, and team effectiveness. In: Linking Emotional Intelligence and Performance at Work: Current Research Evidence with Individuals and Groups. 2006:145-163.

41. Chon D, Sitkin SB. Disentangling the process and content of self-awareness: a review, critical assessment, and synthesis. Acad Manag Ann. 2021;15(2):607-651. doi:10.5465/annals.2018.0079

42. Daud Y. Self-leadership and its application to today's leader-A review of literature. Strateg J Bus Change Manag. 2020;8(1):1-11.

43. Bracht EM, Keng-Highberger FT, Avolio BJ, Huang Y. Take a "Selfie": examining how leaders emerge from leader self-awareness, self-leadership, and self-efficacy. Front Psychol. 2021;12:653.

44. Carden J, Jones RJ, Passmore J. An exploration of the role of coach training in developing self-awareness: a mixed methods study. Curr Psychol. 2021:1-15. doi:10.1007/s12144-021-01929-8

45. Goleman D, Boyatzis RE, McKee A. Primal Leadership: Unleashing the Power of Emotional Intelligence. Harvard Business Press; 2013.

46. Fontaine P. Identification and economic behavior sympathy and empathy in historical perspective. Econ Philos. 1997;13 (2):261-280. doi:10.1017/S026626710000451X

47. Bruni L, Sugden R. Moral canals: trust and social capital in the work of Hume, Smith and Genovesi. Econ Philos. 2000;16(1):21-45. doi:10.1017/S0266267100000122

48. Schertz MV. Empathy as intersubjectivity: resolving Hume and Smith's divide. Stud Philos Educ. 2007;26(2):165-178. doi:10.1007/ s11217-006-9022-2

49. Kirman A, Teschl M. Selfish or selfless? The role of empathy in economics. Philos Trans $R$ Soc Lond B Biol Sci. 2010;365 (1538):303-317. doi:10.1098/rstb.2009.0192

50. Scheres A, Sanfey AG. Individual differences in decision making: drive and reward responsiveness affect strategic bargaining in economic games. Behav Brain Func. 2006;2(1):35. doi:10.1186/1744-9081-2-35

51. Dijk van E, Ckwd D. Experimental games and social decision making. Ann Rev Psychol. 2021;72(1):415-438. doi:10.1146/ annurev-psych-081420-110718

52. Loewenstein G. Emotions in economic theory and economic behavior. Am Econ Rev. 2000;90(2):426-432. doi:10.1257/aer.90.2.426

53. Peters E, Västfjäll D, Gärling T, Slovic P. Affect and decision making: a "hot" topic. J Behav Decis Mak. 2006;19(2):79-85. doi: $10.1002 / \mathrm{bdm} .528$

54. Kahneman D, Tversky A. On the interpretation of intuitive probability: a reply to Jonathan Cohen; 1979.

55. Loewenstein G, O’Donoghue T. Animal spirits: affective and deliberative processes in economic behavior. Available at SSRN 539843; 2004

56. Naqvi N, Shiv B, Bechara A. The role of emotion in decision making: a cognitive neuroscience perspective. Curr Dir Psychol Sci. 2006;15(5):260-264. doi:10.1111/j.1467-8721.2006.00448.x

57. Riaz MN, Riaz MA, Batool N. Managerial decision making styles as predictors of personal and organizational outcomes of in-service employees. J Behav Sci. 2014;24(2):100.

58. Slovic P, Finucane ML, Peters E, MacGregor DG. The affect heuristic. Eur J Oper Res. 2007;177(3):1333-1352. doi:10.1016/j. ejor.2005.04.006

59. Bradley MM, Lang PJ. Emotion and motivation; 2007. 
60. Heilman RM, Crişan LG, Houser D, Miclea M, Miu AC. Emotion regulation and decision making under risk and uncertainty. Emotion. 2010;10(2):257. doi:10.1037/a0018489

61. Gross JJ. Emotion regulation: affective, cognitive, and social consequences. Psychophysiology. 2002;39(3):281-291. doi:10.1017/ S0048577201393198

62. Newell B, Bröder A. Cognitive processes, models and metaphors in decision research. Judgm Decis Mak. 2008;3(3):195.

63. Mojsa-Kaja J, Szklarczyk K, González-Yubero S, Palomera R. Cognitive emotion regulation strategies mediate the relationships between Dark Triad traits and negative emotional states experienced during the COVID-19 pandemic. Pers Individ Dif. 2021;181:111018. doi:10.1016/j.paid.2021.111018

64. Canli T, Ferri J, Duman E. Genetics of emotion regulation. Neuroscience. 2009;164(1):43-54. doi:10.1016/j.neuroscience.2009.06.049

65. Shapira-Lishchinsky O, Levy-Gazenfrantz T. The multifaceted nature of mentors' authentic leadership and mentees' emotional intelligence: a critical perspective. Educ Manag Admin Leader. 2016;44 (6):951-969. doi:10.1177/1741143215595413

66. Mintzberg H. Strategy-making in three modes. Calif Manage Rev. 1973;16(2):44-53. doi:10.2307/41164491

67. Akbar A. Does frequent leadership changes influence firm performance? Insights from China. Insights from China (July 27, 2021). Akbar A, Jiang, X, Fareed, Z, and Akbar, M; 2021:291-298.

68. Schiltz HK, Magnus BE, McVey AJ, et al. A psychometric analysis of the social anxiety scale for adolescents among youth with autism spectrum disorder: caregiver-adolescent agreement, factor structure, and validity. Assessment. 2021;28(1):100-115. doi:10.1177/1073191119851563

69. Riggio RE, Zimmerman J. Social skills and interpersonal relationships: influences on social support and support seeking. Adv Pers Relatsh. 1991;2:133-155.

70. Richter NF, Martin J, Hansen SV, Taras V, Alon I. Motivational configurations of cultural intelligence, social integration, and performance in global virtual teams. J Bus Res. 2021;129:351-367. doi:10.1016/j.jbusres.2021.03.012

71. Heilman RM, Miu AC, Houser D. Emotion regulation and economic decision-making. In: Neuroeconomics. Springer; 2016: 113-131.

72. Miu AC, Heilman RM, Houser D. Anxiety impairs decision-making: psychophysiological evidence from an Iowa gambling task. Biol Psychol. 2008;77(3):353-358. doi:10.1016/j.biopsycho.2007.11.010

73. Al-Dabbagh ZS. The Role of decision-maker in crisis management: a qualitative study using grounded theory (COVID-19 pandemic crisis as a model). J Public Aff. 2020;20(4):e2186.

74. Siegrist M, Bowman G, Mervine E, Southam C. Embedding environment and sustainability into corporate financial decision-making. Account Finance. 2020;60(1):129-147. doi:10.1111/acfi.12533

75. Kim HT, Foroudi P. Linking managers' emotional intelligence, cognitive ability and firm performance: insights from Vietnamese firms. Cogent Bus Manag. 2020;7(1):1829272. doi:10.1080/23311975.2020.1829272

76. Ackert LF, Deaves R, Miele J, Nguyen Q. Are time preference and risk preference associated with cognitive intelligence and emotional intelligence? J Behav Finance. 2020;21(2):136-156. doi:10.1080/ 15427560.2019 .1663850

Psychology Research and Behavior Management

\section{Publish your work in this journal}

Psychology Research and Behavior Management is an international, peer-reviewed, open access journal focusing on the science of psychology and its application in behavior management to develop improved outcomes in the clinical, educational, sports and business arenas. Specific topics covered in the journal include: Neuroscience, memory and decision making; Behavior modification and management; Clinical
77. Mertens DM. Research and Evaluation in Education and Psychology: Integrating Diversity with Quantitative, Qualitative, and Mixed Methods. Sage publications; 2014.

78. Taherdoost H. Sampling methods in research methodology; how to choose a sampling technique for research. How to Choose a Sampling Technique for Research (April 10, 2016); 2016.

79. Gupta S, Shabbir J. On improvement in estimating the population mean in simple random sampling. J Appl Stat. 2008;35(5):559-566. doi: $10.1080 / 02664760701835839$

80. Olsen C, St George D. Cross-sectional study design and data analysis. CEEB. 2004;26(3):2006.

81. Gietl S, Göttsche M, Habisch A, Roloff M, Schauer M. Does CSR reporting destroy firm value? Empirical evidence on GRI-aligned European firms. Empirical Evidence on GRI-aligned European Firms (December 1, 2012); 2012.

82. Leech NL, Barrett KC, Morgan GA. EIBM SPSS for Intermediate Statistics: Use and Interpretation. Routledge; 2014.

83. Hayes AF, Coutts JJ. Use omega rather than Cronbach's alpha for estimating reliability. But. Commun Methods Meas. 2020;14(1):1-24. doi:10.1080/19312458.2020.1718629

84. Falk CF, Savalei V. The relationship between unstandardized and standardized alpha, true reliability, and the underlying measurement model. J Pers Assess. 2011;93(5):445-453. doi:10.1080/ 00223891.2011 .594129

85. Chan LL, Idris N. Validity and reliability of the instrument using exploratory factor analysis and Cronbach's alpha. Int J Acad Res Bus Soc Sci. 2017;7(10):400-410. doi:10.6007/IJARBSS/v7-i10/3387

86. Stanley TD, Jarrell SB. Meta-regression analysis: a quantitative method of literature surveys. J Econ Surv. 2005;19(3):299-308. doi:10.1111/j.0950-0804.2005.00249.x

87. Zeb S, Akbar A, Gul A, Haider SA, Poulova P, Yasmin F. Work-Family conflict, emotional intelligence, and general self-efficacy among medical practitioners during the COVID-19 pandemic. Psychol Res Behav Manag. 2021;14:1867. doi:10.2147/PRBM.S333070

88. Vasconcelos AF. Pursuing organizational spirituality: some lessons from a financial services corporation. Manag Mark. 2011;6(3):365.

89. Tanveer MA, Akbar A, Gill H, Ahmed I. Role of personal level determinants in entrepreneurial firm's success. J Basic Appl Sci Res. 2013;3(1):449-458.

90. Huang H, Liu L, Yang S, Cui X, Zhang J, Wu H. Effects of job conditions, occupational stress, and emotional intelligence on chronic fatigue among Chinese nurses: a cross-sectional study. Psychol Res Behav Manag. 2019;7:351. doi:10.2147/PRBM.S207283

91. Szcześniak M, Rodzeń W, Malinowska A, Kroplewski Z. Big five personality traits and gratitude: the role of emotional intelligence. Psychol Res Behav Manag. 2020;13:977.

92. Hossain SM, Akbar A, Tehseen S, et al. Evaluation of entrepreneurs success: a special reference to women entrepreneurs in Bangladesh. Acad Entrep J. 2021;27:1-3. applications; Business and sports performance management; Social and developmental studies; Animal studies. The manuscript management system is completely online and includes a very quick and fair peer-review system, which is all easy to use. Visit http://www. dovepress.com/testimonials.php to read real quotes from published authors. 